\title{
The Association between 5-Hydroxytryptamine Receptor 1B rs13212041 Polymorphism and Trait Anxiety in Chinese Han College Subjects
}

\author{
Xiaofei Ruan ${ }^{1}$, Suwen Fang ${ }^{2}$, Qi Zheng ${ }^{2}$, Senqing $\mathrm{Qi}^{2}$, Yingfang Tian ${ }^{1, *}$ and Wei Ren ${ }^{1, *}$ \\ 1 Key Laboratory of Modern Teaching Technology, Ministry of Education, Xi'an 710062, China; rxf@snnu.edu.cn \\ 2 College of Life Sciences, Shaanxi Normal University, Xi'an 710119, China; 202456@snnu.edu.cn (S.F.); \\ zq182069@snnu.edu.cn (Q.Z.); qisenqing@snnu.edu.cn (S.Q.) \\ * Correspondence: yingfang_tian@snnu.edu.cn (Y.T.); renwei@snnu.edu.cn (W.R.)
}

check for

updates

Citation: Ruan, X.; Fang, S.; Zheng, Q.; Qi, S.; Tian, Y.; Ren, W. The

\section{Association between}

5-Hydroxytryptamine Receptor 1B rs13212041 Polymorphism and Trait Anxiety in Chinese Han College Subjects. Life 2021, 11, 882. https:// doi.org/10.3390/life11090882

Academic Editors: Rossella Miele and Roberta Lattanzi

Received: 5 July 2021

Accepted: 24 August 2021

Published: 27 August 2021

Publisher's Note: MDPI stays neutral with regard to jurisdictional claims in published maps and institutional affiliations.

Copyright: (c) 2021 by the authors. Licensee MDPI, Basel, Switzerland. This article is an open access article distributed under the terms and conditions of the Creative Commons Attribution (CC BY) license (https:/ / creativecommons.org/licenses/by/ $4.0 /)$.

\begin{abstract}
Trait anxiety is a vulnerable personality factor for anxiety and depression. High levels of trait anxiety confer an elevated risk for the development of anxiety and other psychiatric disorders. There is evidence that 5-hydroxytryptamine receptor 1B (5-HT1B) gene polymorphisms play an important role in emotional disorders. Genotyping for four single-nucleotide polymorphisms (SNP) (rs11568817, rs130058, rs6297, and rs13212041) was conducted for 388 high trait anxious (HTA) individuals and 463 low traitanxious (LTA) individuals in Chinese Han college subjects. The results showed that the frequencies of the C-allele and TC + CC genotype of rs13212041 in the LTA individuals were higher than that in the HTA individuals ( $p=0.025$ and $p=0.014$, respectively). Both the $C$-allele and TC $+C C$ genotype were associated with trait anxiety decreasing $(\mathrm{OR}=0.771$ and $\mathrm{OR}=0.71$, respectively). Furthermore, different gene model analysis also showed that the $\mathrm{C}$ allele was a protective factor for trait anxiety in Chinese Han college subjects. These findings suggest that 5-HT1B rs13212014 may play a role in trait anxiety among China Han college subjects. The rs13212014 polymorphism may be involved in decreasing the risk of trait anxiety. These results also provide a novel insight into the molecular mechanism underlying trait anxiety.
\end{abstract}

Keywords: 5-hydroxytryptamine receptor 1B (5-HT1B); gene polymorphisms; single-nucleotide polymorphisms (SNP); trait anxiety; association

\section{Introduction}

Trait anxiety is defined as an individual's disposition to experience frequent and intense anxiety and worry in response to various stress situations. Individuals with high trait-anxious (HTA) are considered more susceptible to clinical anxiety and depression [1,2], which refers to individuals with HTA as pre-existing forms of anxiety. A large number of behavioral studies have revealed that individuals with HTA exhibit cognitive and emotional disorders, which are similar to anxiety disorders and behavioral biases, such as excessive uneasiness and concern about uncertain events on critical symptoms, threatening information, attention bias, persistent attention, low tolerance for uncertain information, and rejection or dislike of negative results or information [3-5]. The reasons for those results may be related to the information processing efficiency caused by anxious emotion [6]. Evidence from these studies indicates that individuals with high trait anxiety have similar behavioral performance compared to anxiety disorders. Most importantly, there is consistency that excessive concerns about uncertainty point to the developmental links between high trait anxiety and anxiety disorders.

Serotonin (5-HT) is an important signaling molecule and neurotransmitter, which is widely distributed in the central nervous system and surrounding tissues. In recent years, molecular genetic studies have shown that dysfunction of the 5-HT is closely related to anxiety, depression, loss of appetite, sleeping nap, decreased activity, sexual dysfunction, 
endocrine function disorder, etc. 5-HT is involved in the regulation of various mental activities and is closely related to psychiatric diseases. Almost all serotonin receptor subtypes are involved in antidepressant or anxiolytic effects [7]. 5-hydroxytryptamine receptor 1B(5-HT1B), an inhibitory G-protein coupled metabotropic receptor that decreases cAMP, is highly expressed in the striatum, pallidum, accumbens nucleus, substantia nigra, and ventral tegmental area [8]. 5-HT1B plays an important role in regulating serotonergic neurotransmission. It has been reported that the function of 5-HT1Bacts both presynaptically, as an inhibitory autoreceptor located on terminals of serotonin neurons and postsynaptically, as an inhibitory heteroreceptorcontrolling the release of other neurotransmitters [9].

Various animal studies have also demonstrated that 5-HT1B plays a role in anxiety-like and anxiolytic-like effects. 5-HT1B gene knockout mice exhibited reduced anxiety and hyperactivity [10]. Nautiyal and colleagues showed that the forebrain 5-HT1B heteroreceptors expressed during an early postnatal period might contribute to the development of the neural systems underlying adult aggression and proved that distinct heteroreceptors acting during adulthood were involved in mediating impulsivity [11]. Interestingly, mice lacking 5-HT1B autoreceptors presented decreased anxiety in the open field test [9]. Similarly, studies byLin and Parsons [12] indicated that stimulation of 5-HT1B receptor increased anxiety-like behavior in the elevated plus-maze test in rats, suggesting the role of this receptor subtype in the pathology and treatment of anxiety. Non-selective 5-HT1B/1D receptors agonist GR127935 also showed anxiolytic-like properties [13]. The observed antianxiety-like effect might be linked to the postsynaptic 5-HT1B receptors or/and 5HT1B heteroreceptors [14]. These studies suggested that the 5-HT1B receptor might play an important role in trait anxiety. However, its exact role is yet unclear.

Previous human studies reported the associations between the different polymorphisms in the gene coding for 5-HT1B and alcohol dependence [15,16], alcohol abuse [17], aggressive behaviour [18,19], anger and hostility [20], attention-deficit/hyperactivity disorder (ADHD) [21], substance abuse [22], and schizophrenia [23,24]. Although the current genome-wide literature could not find an association of 5-HT1B with anxiety or related phenotypes, including depression and neuroticism in some European populations [25-27], a few studies have reported the associations between the different polymorphisms in 5-HT1B and some phenotypes, including anxiety and depression in Chinese and Americans [28-31]. The most frequently studied 5-HT1B gene variants are rs6296, rs13212041, rs6297, rs11568817, and rs130058. Both rs11568817 and rs130058 were significantly associated with substance use disorders, while rs11568817 was associated with nicotine dependence in men with ADHD. Alcohol-dependent individuals with rs13212041 CC genotype were more frequent compared to the carriers of the $\mathrm{T}$ allele in the group with early onset of alcohol abuse [17]. The $3^{\prime}$-untranslated region (3'-UTR) variant rs13212041 potentially enables the microRNA-mediated regulation of 5-HT1B expression [20]. The variant of rs6296 has been associated with attention-deficit hyperactivity disorder [32], aggressive behavior in children [33], substance misuse disorder, and major depression [31]. These allelic associations with trait anxiety are not consistently found. The etiology and pathogenesis of trait anxiety are still largely unclear. It is commonly believed that trait anxiety results from different underlying neurobiological mechanisms, such as genetic and environmental influences. Thus, we hypothesized that 5-HT1B might be involved in the development of trait anxiety in Chinese Han college students.

To our knowledge, this is the first study to examine the association between 5-HT1B gene polymorphism and trait anxiety in Chinese Han subjects. The results might provide novel insights into the serotonergic regulation mechanisms underlying trait anxiety; it could also help further differentiation of trait anxiety and potential improvement of the prediction for anxiety disorders. 


\section{Materials and Methods}

\subsection{Participants}

All participants provided written informed consent. The study protocol was approved by the ethics committee of Shaanxi Normal University. Participants in the study were Chinese Han subjects recruited from freshman or senior years. Subjects were asked to provide venous blood samples and fill out the State-Trait Anxiety Inventory (STAI) (Wenli Li, 1995; Spielberger et al., 1983). The trait anxiety subscale is intended to measure the predisposition to experience chronically high levels of anxiety. The number of participants that filled out State-Trait Anxiety Inventory (STAI) was 2645, with 2529 valid questionnaires being received. Among the 2529 individuals, we filtered the top 25\% of the participants as the HTA group (case, 632) and the last $25 \%$ of the participants as the LTA group (control, 632), followed by the score of STAI by SPSS quartile method [34,35]. However, some individuals were unwilling to provide blood samples. At last, 851 participants with valid DNA and valid data were enrolled for our study, including 388 individuals with HTA and age- and gender-matched 463 individuals with LTA, as shown in Table 1 . The classic case-control research paradigm was conducted in our research. A questionnaire test (posttest) was performed on the subjects before genotyping, according to the self-report of participants. All the participants had no history of long-term medication, no symptoms of mental or neurological disorders.

Table 1. Clinical characteristics.

\begin{tabular}{ccccc}
\hline & LTA & HTA & $t$ & $p$-Value \\
\hline Valid & 463 & 388 & & \\
participants & & & 1.208 & 0.227 \\
Gender & 86 & 85 & & \\
Male & 377 & 303 & & \\
Female & $19.11 \pm 2.50$ & $19.04 \pm 2.45$ & 0.414 & 0.230 \\
Age (SD) & $31.39 \pm 4.11$ & $54.27 \pm 5.28$ & -71.076 & $<0.001$ \\
STAI & & & & \\
\hline
\end{tabular}

HTA, high trait anxious; LTA, low trait anxious.

\subsection{Blood Collection and DNA Isolation}

Peripheral blood samples $(2 \mathrm{~mL})$ were obtained from each participant. Genomic DNA was extracted from peripheral blood of cases and controls using the GoldMag-Mini whole blood Genomic DNA Purification Kit (GoldMagCo. Ltd., Xi'an, China), as recommended by the manufacturer's instructions. DNA concentration was determined by the NanoDrop Lite spectrophotometer (Thermo Fisher Scientific, Waltham, MA, USA). The concentration of all DNA samples was normalized to $20 \mathrm{ng} / \mu \mathrm{L}$.

\subsection{SNP Selection}

SNP inclusion and screening criteria were as follows: (1) based on the GRCh37 database (http:/ / asia.ensembl.org/Homo_sapiens/Info/Index, accessed on 10 May 2020), we downloaded the ped file and info file for the variations of 5-HT1B (Chromosome 6:77460924-77463491) and nearby regulatory regions ( $\pm 2 \mathrm{~kb})$ in CHB and CHS population. (2) Using Haploview software, we selected tagSNPs based on HWE > 0.05, MAF > 0.1, Min Genotype $>75 \%$, and Tagger $\mathrm{r}^{2}>0.8$. (3) as the function of the 5-HT1B gene coding region has been studied extensively, SNPs located within 5-HT1B gene regulatory regions were selected. (4) we selected tagSNPs by combined MassARRAY primer design software, HWE $>0.05, \mathrm{MAF}>0.1$ and the call rate $>95 \%$ in our study population. (5) based on prior reports, polymorphisms in 5-HT1B have been well studied in other mental disorders, including alcohol abuse [17], ADHD comorbidities [21], anger and hostility [20], schizophrenia [24], anxiety and depression [28-31], but current knowledge of the association between trait anxiety and 5-HT1B gene polymorphisms in the Chinese Han population that have not been 
well studied were included. Finally, four polymorphisms in 5-HT1B, including rs11568817, rs130058, rs6297, and rs13212041, were randomly selected in this study.

\subsection{Genotyping}

These four 5-HT1B gene polymorphisms were genotyped according to the procedure of iPLEX single base extension amplification technology. MassARRAY Nano dispenser (Agena Bioscience, San Diego, CA, USA) was used to design primers for the amplification process and single-base extension reactions. SNP genotyping was carried out on the MassARRAYiPLEX (AgenaBiosience, San Diego, CA, USA) platform. Agena Bioscience Typer 4.0 software was used to manage and analyze SNP genotypic data. iPLEX primer for 5-HT1B genotyping in this work, as listed in Table 2. The steps involved in the generation of SNP genotypes using the iPLEX chemistry were based on the manufacturer's protocol, as following: regions targeted by the multiplex assay are amplified by PCR. PCR products are shrimp alkaline phosphatase (SAP) treated to neutralize unincorporated nucleotides. An extension reaction was then performed to extend the PCR fragments by one base into the SNP site. To remove salts from the iPLEX products prior to mass spectrometry, clean resin ion exchange resin was used. The Nanodispenser RS1000 or other compatible dispenserinstrument is used to transfer resin-cleaned iPlex products (analytes) from 384well plates to SpectroCHIPs. The mass of the resultant extended fragments is then measured using MALDI-TOF, resulting in a spectrum of distinct mass peaks for the multiplex reaction. In addition, this study also set up double wells for each sample during all the processes (including PCR amplification and mass spectrometry) to ensure the accuracy of the results.

Table 2. TheiPLEX primer list.

\begin{tabular}{|c|c|c|c|}
\hline SNP_ID & 2nd-PCRP & 1st-PCRP & UEP_SEQ \\
\hline rs130058 & ACGTTGGATGTCCTCAATTATTCCTCCGCC & ACGTTGGATGTTAGCTAGGCGCTCTGGAAG & GCTGAAACTAGAGGTCA \\
\hline rs11568817 & ACGTTGGATGGTTGTTCCTCTCCACACCG & ACGTTGGATGTTCACССТCСТGCACTAGAC & cttcaTCTCCACACCGGGTCTTAG \\
\hline rs13212041 & ACGTTGGATGCGATTGTCAAGCCACAACTC & ACGTTGGATGGTAAAGTGACAGGTACATGA & сасcCCATTATGTGTGCTAGTGCC \\
\hline rs6297 & ACGTTGGATGGCATTCCATAAACTGATACG & ACGTTGGATGAACTTGGTCCCCAAAGGTCG & agtcAGTGCACAAGTTGACTTGCC \\
\hline
\end{tabular}

\subsection{Data Analysis}

Quantitative data were shown as median \pm standard deviation (SD). The Student's $t$-test was used to compare the differences of quantitative data, and the $\chi^{2}$ test was applied for qualitative data. Deviation from Hardy-Weinberg equilibrium (HWE) of genotypic distribution of each SNP in controls was analyzed using Fisher's exact test. In addition, Pearson's $\chi^{2}$ and Fisher's exact tests were used to calculate the allele frequencies of case and control, and MAF in controls was defined as the baseline. After adjusting for age and gender, odds ratios (ORs), and 95\% confidence interval (95\% CI) were calculated using unconditional logistic regression analysis [36]. The relationship between the selected SNPs and trait anxiety was calculated using genotypic model analysis (codominant, dominant, recessive, over-dominant, and log additive) by SPSS 21 (Chicago, IL, USA) and PLINK software [37]. False-positive report probability (FPRP) analysis was used to evaluate the noteworthy associations of the significant findings. We set 0.2 as an FPRP threshold for an association with genotypes under investigation. Multifactor dimensionality reduction (MDR) (version 3.0.2) was performed to evaluate the SNP-SNP interactions in the risk of trait anxiety. Pairwise linkage disequilibrium (LD) was produced using Haploview 4.2 software. Haplotypes analysis was calculated using unconditional logistic regression analysis.In addition to statistical analysis, we also conducted several bioinformatics analyses for the identified SNPs of 5-HT1B. The SNPs information of 5-HT1B was retrieved from the National Center for Biotechnology Information (NCBI) database of dbSNP (http://www.ncbi.nlm.nih.gov/snp/ (accessed on 10 May 2020)). The bioinformatics tools, including SNPinfo Web Server (https://snpinfo.niehs.nih.gov/snpinfo/index.html (accessed on 3 December 2020)) and HaploReg v4.1 (https:/ / pubs.broadinstitute.org/mammals/haploreg/haploreg.php (ac- 
cessed on 3 January 2021)) were used to identify the potential functional SNPs in human 5-HT1B Statistical analyses were performed using Microsoft Excel (Microsoft Corporation, Redmond, WA, USA) and SPSS (SPSS 21, Chicago, IL, USA)) statistical package. In the study, all the $p$-value were two-sided, and $p<0.05$ was defined as statistically significant, whereas a value of corrected $p<0.05 / 4$ was considered significant after Bonferroni correction.

\section{Results}

\subsection{Clinical Characteristics of Samples}

The characteristics of the enrolled participants are presented in Table 1. 851 participants were enrolled in this study, including 463 individuals with HTA and 388 individuals with LTA. The average STAI score was higher in the HTA group than in the LTA group $(t=-71.076, p<0.001)$. There is no significant difference between the HTA and LTA group in terms of gender $(t=1.208, p=0.227)$ or age $(t=0.414, p=0.230)$.

\subsection{Basic Characteristic of SNP}

Four SNPs in 5-HT1B, including rs11568817, rs130058, rs6297, and rs13212041 (MAF $\geq 0.1$ ), were selected for this study. The basic characteristic of SNPs in the enrolled population is shown in Table 3. All the four SNPs were in HWE in the study $(p>0.05)$. The call rate of all the four SNPs was $100 \%$.

Table 3. Basic characteristic of SNPs in the enrolled population.

\begin{tabular}{|c|c|c|c|c|c|c|c|c|}
\hline \multirow{2}{*}{ rs \# } & \multirow{2}{*}{ Chr.pos } & \multirow{2}{*}{ Region } & \multirow{2}{*}{$\begin{array}{l}\text { Minor } \\
\text { Allele }\end{array}$} & \multicolumn{2}{|c|}{$p$-Value for HWE Test } & \multirow{2}{*}{ Call Rate } & \multirow{2}{*}{ Haploreg } & \multirow{2}{*}{$\begin{array}{l}\text { SNPinfo Web } \\
\text { Server }\end{array}$} \\
\hline & & & & HTA & LTA & & & \\
\hline rs13212041 & $6: 77461407$ & 3'-UTR & $\mathrm{C}$ & 0.356 & 0.666 & $100 \%$ & $\begin{array}{l}\text { Promoter histone marks, DNAse, } \\
\text { Proteins bound (FOS) }\end{array}$ & $\begin{array}{l}\text { hsa-miR-622, } \\
\text { hsa-miR-96 }\end{array}$ \\
\hline rs6297 & $6: 77462224$ & $3^{\prime}$-UTR & $\mathrm{C}$ & 1.000 & 0.713 & $100 \%$ & $\begin{array}{c}\text { Promoter histone marks, Enhancer } \\
\text { histone marks, DNAse, Motifs } \\
\text { changed (Zbtb3) }\end{array}$ & $\begin{array}{l}\text { Splicing (ESE } \\
\text { or ESS) }\end{array}$ \\
\hline rs130058 & $6: 77463564$ & $5^{\prime}$-UTR & A & 0.781 & 0.757 & $100 \%$ & $\begin{array}{c}\text { Promoter histone marks, Enhancer } \\
\text { histone marks, DNAse, Motifs } \\
\text { changed }\end{array}$ & TFBS \\
\hline rs11568817 & $6: 77463665$ & 5'-UTR & $\mathrm{C}$ & 0.501 & 0.633 & $100 \%$ & $\begin{array}{l}\text { Promoter histone marks, Enhancer } \\
\text { histone marks, DNAse }\end{array}$ & TFBS \\
\hline
\end{tabular}

MAF, minor allele frequency; HWE, Hardy-Weinberg equilibrium; HTA, high trait anxious group; LTA, low trait anxious group; TFBS, transcription factor binding sites. \#, SNP ID.

Table 3 shows the basic information and the potential function of the selected SNPs. By HaploReg annotation, we found that the selected SNPs were associated with regulation of promoter and/or enhancer histone marks, DNase, proteins bound, and motifs changed. Based on the SNPinfo web server database, rs13212041 might be related to the binding of hsa-miR-622 and hsa-miR-96. Rs6297 was associated with splicing. Moreover, rs130058 and rs11568817 may be located within a transcription factor binding site (TFBS).

\subsection{Allele and Genotype Frequencies Analysis of SNPS}

A summary of allele and genotype frequencies is presented in Table 4 . The allele "C" of rs13212041 in 5-HT1Bwas significantly associated with trait anxiety in the study population $(\mathrm{OR}=0.77,95 \% \mathrm{CI}=0.61-0.97, p=0.025)$. Individuals carrying the "TC" genotype were significantly more frequent $(\mathrm{OR}=0.70,95 \% \mathrm{CI}=0.53-0.94, p=0.019)$ in the subjects with LTA than those with HTA. However, no significant association was found after Bonferroni correction.

\subsection{Association Analysis}

The association between SNPs genotypes and trait anxiety under various genetic model is shown in Table 5. Our analysis showed that crude analysis of rs13212041 was significantly associated with the developing of trait anxiety under the over-dominant model $(\mathrm{OR}=0.72,95 \% \mathrm{CI}=0.54-0.96, p=0.024), \log$-additive model $(\mathrm{OR}=0.77,95 \% \mathrm{CI}=0.62-0.97$, 
$p=0.025)$, and the dominant model $(\mathrm{OR}=0.71,95 \% \mathrm{CI}=0.54-0.93, p=0.014)$. However, no significant association was found after Bonferroni correction.

Table 4. Association between SNPs and trait anxiety.

\begin{tabular}{|c|c|c|c|c|}
\hline SNP & Control $n(\%)$ & Case $n(\%)$ & ORs $(95 \%$ CI $)$ & $p$-Value \\
\hline \multicolumn{5}{|l|}{ rs13212041 } \\
\hline Genotype & & & - & \\
\hline TT & $255(55.1)$ & $246(63.4)$ & 1 & - \\
\hline $\mathrm{TC}$ & $180(38.9)$ & $122(31.4)$ & $0.70(0.53-0.94)$ & 0.019 * \\
\hline $\mathrm{CC}$ & $28(6.1)$ & $20(5.2)$ & $0.74(0.41-1.35)$ & 0.366 \\
\hline \multicolumn{5}{|l|}{ Allele } \\
\hline $\mathrm{T}$ & $690(74.5)$ & $614(79.1)$ & 1 & - \\
\hline $\mathrm{C}$ & $236(25.5)$ & $162(20.9)$ & $0.77(0.61-0.97)$ & 0.025 * \\
\hline \multicolumn{5}{|l|}{ rs6297 } \\
\hline Genotype & & & - & \\
\hline TT & 357 (77.1) & $306(78.9)$ & 1 & - \\
\hline $\mathrm{TC}$ & $98(21.2)$ & 77 (19.9) & $0.92(0.66-1.28)$ & 0.670 \\
\hline $\mathrm{CC}$ & $8(1.7)$ & $5(1.3)$ & $0.73(0.24-2.25)$ & 0.780 \\
\hline \multicolumn{5}{|l|}{ Allele } \\
\hline $\mathrm{T}$ & 812 (87.7) & $689(88.8)$ & 1 & - \\
\hline $\mathrm{C}$ & $114(12.3)$ & 87 (11.218) & $0.90(0.67-1.21)$ & 0.484 \\
\hline \multicolumn{5}{|l|}{ rs130058 } \\
\hline Genotype & & & - & \\
\hline TT & $389(84.0)$ & $315(81.0)$ & 1 & \\
\hline TA & $72(15.6)$ & $69(17.8)$ & $0.48(0.09-2.70)$ & 0.395 \\
\hline $\mathrm{AA}$ & $2(0.4)$ & $4(1.0)$ & $0.41(0.07-2.23)$ & 0.282 \\
\hline \multicolumn{5}{|l|}{ Allele } \\
\hline $\mathrm{T}$ & $850(91.8)$ & $699(90.1)$ & 1 & - \\
\hline A & $76(8.2)$ & $77(9.9)$ & $1.23(0.88-1.72)$ & 0.218 \\
\hline \multicolumn{5}{|l|}{ rs11568817 } \\
\hline Genotype & & & - & \\
\hline AA & 367 (79.3) & $295(76.0)$ & 1 & - \\
\hline$A C$ & $92(19.9)$ & $85(21.9)$ & $0.46(0.13-1.59)$ & 0.245 \\
\hline $\mathrm{CC}$ & $4(0.9)$ & $8(2.1)$ & $0.40(0.12-1.35)$ & 0.127 \\
\hline \multicolumn{5}{|l|}{ Allele } \\
\hline $\mathrm{A}$ & $826(89.2)$ & $675(87.0)$ & 1 & - \\
\hline $\mathrm{C}$ & $100(10.8)$ & $101(13.0)$ & $1.24(0.92-1.66)$ & 0.158 \\
\hline
\end{tabular}

SNP, single nucleotide polymorphism; CI, confidence interval; OR, odds ratio. Notes: $p$-value wascalculated by logistic regression adjusted for age and gender. ${ }^{*} p<0.05$. Case, the high trait anxiety group; Control: the low trait anxiety.

Table 5. Association between SNPs genotypes and trait anxiety.

\begin{tabular}{|c|c|c|c|c|}
\hline \multirow[b]{2}{*}{ rs \# } & \multicolumn{2}{|c|}{ Group } & \multicolumn{2}{|c|}{ Adjust Analysis } \\
\hline & $\begin{array}{c}\text { Control } \\
(\%)\end{array}$ & $\begin{array}{c}\text { Case } \\
(\%)\end{array}$ & ORs $(95 \% \mathrm{CI})$ & $p$-Value \\
\hline \multicolumn{5}{|l|}{ rs13212041 } \\
\hline \multicolumn{5}{|c|}{ Dominant model } \\
\hline TT & $255(55.1)$ & $246(63.4)$ & 1.00 & - \\
\hline $\mathrm{T} / \mathrm{C}+\mathrm{C} / \mathrm{C}$ & $208(44.9)$ & $142(36.6)$ & $0.71(0.54-0.93)$ & $0.014 *$ \\
\hline \multicolumn{5}{|c|}{ Recessive model } \\
\hline $\mathrm{T} / \mathrm{T}+\mathrm{T} / \mathrm{C}$ & $435(94.0)$ & $368(94.8)$ & 1.00 & - \\
\hline $\mathrm{C} / \mathrm{C}$ & $28(6.0)$ & $20(5.2)$ & $0.84(0.47-1.52)$ & 0.057 \\
\hline \multicolumn{5}{|c|}{ Overdominant model } \\
\hline $\mathrm{T} / \mathrm{T}+\mathrm{C} / \mathrm{C}$ & $283(61.1)$ & $266(68.6)$ & 1.00 & \\
\hline $\mathrm{T} / \mathrm{C}$ & $180(38.9)$ & $122(31.4)$ & $0.72(0.54-0.96)$ & $0.024 *$ \\
\hline \multicolumn{5}{|c|}{ log-Additive model } \\
\hline $0,1,2$ & $463(54.4)$ & $388(45.6)$ & $0.77(0.62-0.97)$ & $0.025 *$ \\
\hline
\end{tabular}


Table 5. Cont.

\begin{tabular}{|c|c|c|c|c|}
\hline \multirow[b]{2}{*}{ rs \# } & \multicolumn{2}{|c|}{ Group } & \multicolumn{2}{|c|}{ Adjust Analysis } \\
\hline & $\begin{array}{c}\text { Control } \\
(\%)\end{array}$ & $\begin{array}{l}\text { Case } \\
(\%)\end{array}$ & ORs $(95 \% \mathrm{CI})$ & $p$-Value \\
\hline \multicolumn{5}{|l|}{ rs6297 } \\
\hline \multicolumn{5}{|c|}{ Dominant model } \\
\hline $\mathrm{TT}$ & $357(77.1)$ & $306(78.9)$ & 1.00 & - \\
\hline $\mathrm{T} / \mathrm{C}+\mathrm{C} / \mathrm{C}$ & $106(22.9)$ & $82(21.1)$ & $0.90(0.65-1.25)$ & 0.537 \\
\hline \multicolumn{5}{|c|}{ Recessive model } \\
\hline $\mathrm{T} / \mathrm{T}+\mathrm{T} / \mathrm{C}$ & 455 (98.3) & $383(98.7)$ & 1.00 & \\
\hline $\mathrm{C} / \mathrm{C}$ & $8(1.7)$ & $5(1.3)$ & $0.74(0.24-2.29)$ & 0.600 \\
\hline \multicolumn{5}{|c|}{ Overdominant model } \\
\hline $\mathrm{T} / \mathrm{T}+\mathrm{C} / \mathrm{C}$ & $365(78.8)$ & $311(80.2)$ & 1.00 & - \\
\hline $\mathrm{T} / \mathrm{C}$ & $98(21.2)$ & $77(19.8)$ & $0.92(0.66-1.29)$ & 0.635 \\
\hline \multicolumn{5}{|c|}{ log-Additive model } \\
\hline $0,1,2$ & $463(54.4)$ & $388(45.6)$ & $0.90(0.67-1.21)$ & 0.486 \\
\hline \multicolumn{5}{|l|}{ rs130058 } \\
\hline \multicolumn{5}{|c|}{ Dominant model } \\
\hline $\mathrm{T} / \mathrm{T}$ & $389(84.0)$ & $315(81.2)$ & 1.00 & - \\
\hline $\mathrm{A} / \mathrm{T}+\mathrm{A} / \mathrm{A}$ & $74(16.0)$ & $73(18.8)$ & $1.22(0.85-1.74)$ & 0.277 \\
\hline \multicolumn{5}{|c|}{ Recessive model } \\
\hline $\mathrm{T} / \mathrm{T}+\mathrm{A} / \mathrm{T}$ & $461(99.6)$ & $384(99.0)$ & 1.00 & - \\
\hline $\mathrm{A} / \mathrm{A}$ & $2(0.4)$ & $4(1.0)$ & $2.40(0.44-13.17)$ & 0.297 \\
\hline \multicolumn{5}{|c|}{ Overdominant model } \\
\hline $\mathrm{T} / \mathrm{T}+\mathrm{A} / \mathrm{A}$ & $391(84.4)$ & $319(82.2)$ & 1.00 & - \\
\hline $\mathrm{A} / \mathrm{T}$ & $72(15.6)$ & $69(17.8)$ & $1.17(0.82-1.69)$ & 0.384 \\
\hline \multicolumn{5}{|c|}{ log-Additive model } \\
\hline $0,1,2$ & $463(54.4)$ & $388(45.6)$ & $1.24(0.88-1.73)$ & 0.216 \\
\hline \multicolumn{5}{|l|}{ rs11568817 } \\
\hline \multicolumn{5}{|c|}{ Dominant model } \\
\hline $\mathrm{A} / \mathrm{A}$ & $367(79.3)$ & $295(76.0)$ & 1.00 & - \\
\hline $\mathrm{A} / \mathrm{C}-\mathrm{C} / \mathrm{C}$ & $96(20.7)$ & $93(24.0)$ & $1.21(0.87-1.67)$ & 0.259 \\
\hline \multicolumn{5}{|c|}{ Recessive model } \\
\hline $\mathrm{A} / \mathrm{A}-\mathrm{A} / \mathrm{C}$ & $459(99.1)$ & $380(97.9)$ & 1.00 & - \\
\hline $\mathrm{C} / \mathrm{C}$ & $4(0.9)$ & $8(2.1)$ & $2.42(0.72-8.08)$ & 0.139 \\
\hline \multicolumn{5}{|c|}{ Overdominant model } \\
\hline $\mathrm{A} / \mathrm{A}-\mathrm{C} / \mathrm{C}$ & $371(80.1)$ & $303(78.1)$ & 1.00 & - \\
\hline $\mathrm{A} / \mathrm{C}$ & $92(19.9)$ & $85(21.9)$ & $1.13(0.81-1.58)$ & 0.466 \\
\hline \multicolumn{5}{|c|}{ log-Additive model } \\
\hline $0,1,2$ & $463(54.4)$ & $388(45.6)$ & $1.24(0.92-1.66)$ & 0.159 \\
\hline
\end{tabular}

SNP, single nucleotide polymorphism; CI, confidence interval, OR, odds ratio. Notes: * $p<0.05$ indicates statistical significance. $p$-values were calculated by two-sided $\chi^{2}$ tests or Fisher's exact tests for each genotype distribution by unconditional logistic regression adjusted for age, gender. Case, the HTA group; Control: the LTA group. \#, SNP ID.

\subsection{FPRP and Power Analysis}

FPRP analysis was carried out to interrogate whether the significant findings was deserving attention (Table 6). At the prior probability level of 0.1 , the significant association for rs13212041 (TC vs. TT, FPRP = 0.189; and T/C + C/C vs. TT, FPRP = 0.146) remained noteworthy.

Rs13212041 polymorphism in 5-HT1B with the risk of trait anxiety were discovered, with power values of 0.641 (TC vs. TT), 0.894 (C vs. T), 0.676 (T/C + C/C vs. TT), 0.700 ( $\mathrm{T} / \mathrm{C}$ vs. $\mathrm{T} / \mathrm{T}+\mathrm{C} / \mathrm{C})$, and 0.889 (log-additive). Especially, the power for the allele and log-additive models was more than $85 \%$, suggesting that the sample size was large enough to discover the differences. 
Table 6. False-positive report of probability values for the associations between 5-HT1B polymorphisms and trait anxiety susceptibility.

\begin{tabular}{|c|c|c|c|c|c|c|c|c|c|}
\hline & \multirow{2}{*}{ Models } & \multirow{2}{*}{ OR $(95 \%$ CI) } & \multirow{2}{*}{$p$} & \multirow{2}{*}{ Statistical Power } & \multicolumn{5}{|c|}{ Prior Probability } \\
\hline & & & & & 0.25 & 0.1 & 0.01 & 0.001 & 0.0001 \\
\hline \multirow{5}{*}{ rs13212041 } & TC vs. TT & $0.70(0.53-0.94)$ & 0.019 & 0.641 & $0.072 *$ & $0.189 *$ & 0.720 & 0.963 & 0.996 \\
\hline & C vs. T & $0.77(0.62-0.97)$ & 0.025 & 0.894 & $0.079 *$ & 0.206 & 0.740 & 0.966 & 0.997 \\
\hline & $\mathrm{T} / \mathrm{C}+\mathrm{C} / \mathrm{C}$ vs. $\mathrm{TT}$ & $0.71(0.54-0.93)$ & 0.014 & 0.676 & 0.054 * & $0.146 *$ & 0.654 & 0.950 & 0.995 \\
\hline & $\mathrm{T} / \mathrm{C}$ vs. $\mathrm{T} / \mathrm{T}+\mathrm{C} / \mathrm{C}$ & $0.72(0.54-0.96)$ & 0.024 & 0.700 & 0.098 * & 0.245 & 0.781 & 0.973 & 0.997 \\
\hline & Log-additive & $0.77(0.62-0.97)$ & 0.025 & 0.889 & $0.082 *$ & 0.212 & 0.747 & 0.968 & 0.997 \\
\hline
\end{tabular}

Statistical power was calculated using the number of observations in the subgroup and the OR and $p$ values in this table. The level of false-positive report probability threshold was set at 0.2 , and noteworthy findings are presented. *—noteworthy findings.

\subsection{MDR Analysis}

MDR was used to analyze the interactions of these four SNPs. The results of the MDR model analysis of the SNP-SNP interactions are demonstrated in Table 7. The results showed that rs13212041 was the best single-locus model to predict trait anxiety (testing accuracy, $0.5455 ; p=0.005$; cross-validation consistency, 10/10). The best multi-loci model was the two-locus model, a combination of rs13212041 and rs6297, with the highest testing accuracy (0.5530) and perfect cross-validation consistency (10/10). As shown in Figure 1, the dendrogram and the Fruchterman-Reingoldgraph described the interactions between these SNPs. The patterns of entropy recapitulate the main and/or interaction effect for each pairwise combination of attributes. The strongest interaction effect was found between rs13212041 and rs6297, with the information gain values of $0.16 \%$, suggesting rs13212041 and rs6297 have synergistic interaction sharing the positive information gain with respect to trait anxiety. Additionally, a combination of rs13212041 and rs6297 was the best model to predict the susceptibility to trait anxiety compared to the single SNP alone.

Table 7. SNP-SNP interaction models of 5-HT1B gene analyzed by the MDR method.

\begin{tabular}{ccccc}
\hline Model & Bal. Acc. CV Training & Bal. Acc. CV Testing & CV Consistency & $p$ \\
\hline rs13212041 & 0.5492 & 0.5455 & $10 / 10$ & 0.0050 \\
rs13212041, rs6297 & 0.5582 & 0.5530 & $10 / 10$ & 0.0008 \\
rs130058, rs13212041, rs6297 & 0.5623 & 0.5480 & $8 / 10$ & 0.0003 \\
rs11568817, rs130058, rs13212041, rs6297 & 0.5658 & 0.5417 & $10 / 10$ \\
\hline
\end{tabular}

MDR, multifactor dimensionality reduction; Bal. Acc., balanced accuracy; CVC, cross-validation consistency; OR, odds ratio; $\mathrm{CI}$, confidence interval. $p$-values were calculated using $\chi^{2}$ tests.
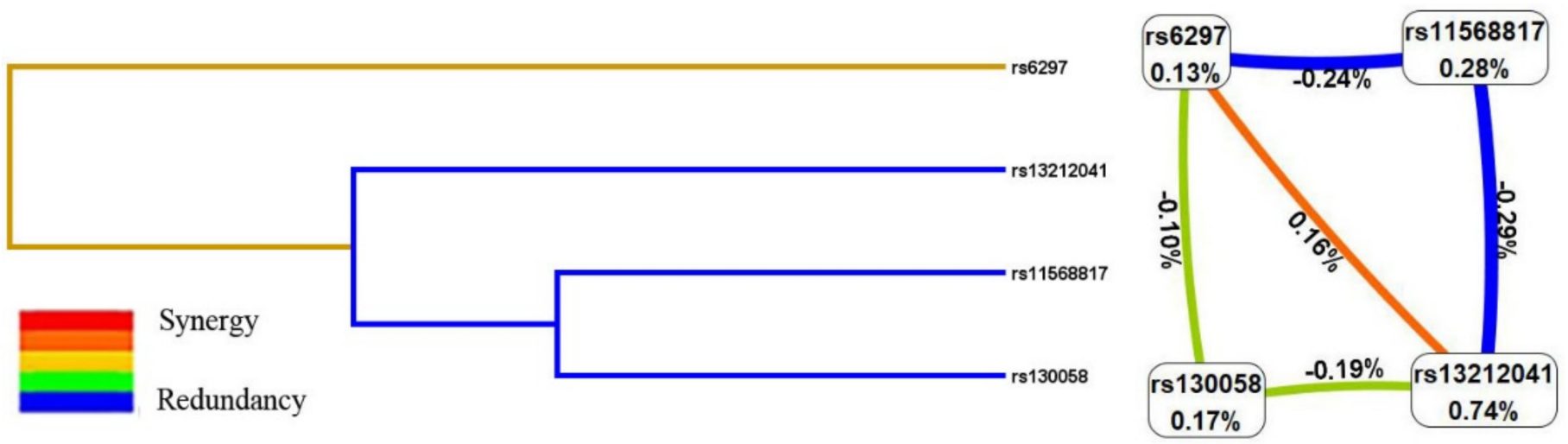

Figure 1. Dendrogram (left) and the Fruchterman-Reingold graph (right) for the interactions between these SNPs. Positive percent entropy indicates synergy, whereas the negative percent indicates redundancy. The orange line indicated positive interaction, green and blue color indicated weak interactions. 


\subsection{LD and Haplotypes Analysis}

Pairwise linkage disequilibrium (LD) and haplotype analyses were conducted for 5-HT1B variants. Figure 2 revealed a LD block in four SNPs (rs13212041, rs130058, rs6297, and rs11568817) with $\mathrm{D}^{\prime}$ values $>0.99$. The frequencies of haplotypes (ATTT, ATCC, ATCT, CATT, and CTTT) and the result of haplotype analysis is showed in Table 8 . The haplotype $\mathrm{C}_{\mathrm{rs} 13212041} \mathrm{~T}_{\mathrm{rs} 130058} \mathrm{~T}_{\mathrm{rs} 6297} \mathrm{~A}_{\mathrm{rs} 11568817}$ may be a protective haplotype in trait anxiety $(\mathrm{OR}=0.71,95 \% \mathrm{CI}=0.52-0.97, p=0.032)$.

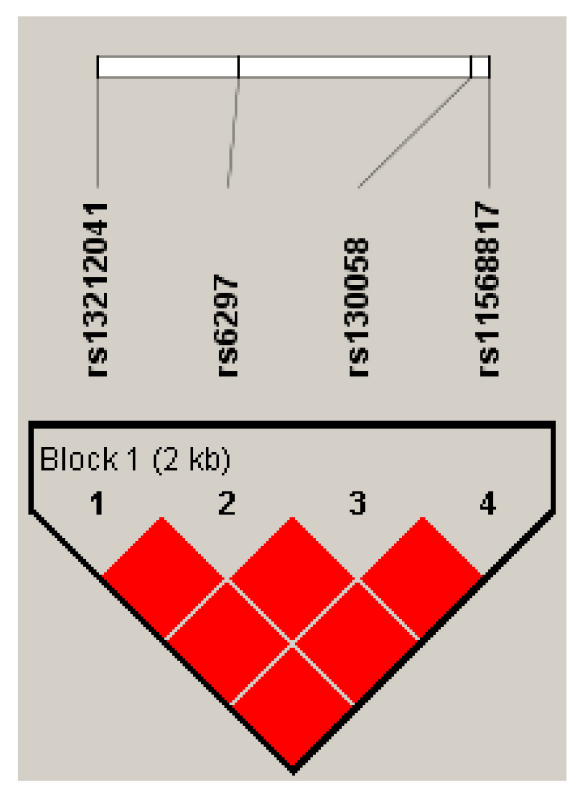

Figure 2. The linkage disequilibrium (LD) plot containing four SNPs from HTR1B gene measured by D'.

Table 8. Haplotype association with response.

\begin{tabular}{ccccccc}
\hline rs13212041 & rs6297 & rs130058 & rs11568817 & Freq & OR (95\% CI) & $p$-Value \\
\hline $\mathrm{T}$ & $\mathrm{T}$ & $\mathrm{T}$ & $\mathrm{A}$ & 0.648 & 1.00 & - \\
$\mathrm{C}$ & $\mathrm{C}$ & $\mathrm{T}$ & $\mathrm{A}$ & 0.118 & $0.87(0.64-1.18)$ & 0.370 \\
$\mathrm{C}$ & $\mathrm{T}$ & $\mathrm{T}$ & $\mathrm{A}$ & 0.116 & $0.71(0.52-0.97)$ & $0.032^{*}$ \\
$\mathrm{~T}$ & $\mathrm{~T}$ & $\mathrm{~A}$ & $\mathrm{C}$ & 0.090 & $1.15(0.82-1.62)$ & 0.420 \\
$\mathrm{~T}$ & $\mathrm{~T}$ & $\mathrm{~T}$ & $\mathrm{C}$ & 0.028 & $1.14(0.63-2.05)$ & 0.660 \\
\hline${ }^{*} p<0.05$ indicates statistical significance. & & & & &
\end{tabular}

\section{Discussion}

College students are increasingly reporting common mental health problems, such as depression and anxiety [35]. It is very important to explore the prevalence and genetic causes of trait anxiety of Chinese college students. 5-HT1B receptor plays important roles in multiple behavioral traits, such as locomotion, feeding, and thermoregulation, and also in arterial contractile regulation mechanisms. The 5-HT1B receptor has been the focus of much neuropsychiatric and neuropharmacological research [38]. The intronless human 5-HT1B, located at 6q14.3-q16.3 (GDB 132312), encodes a 390-amino-acid polypeptide. Many polymorphisms in the coding sequence and UTRs were screened, and multiple correlation studies were carried out in 5-HT1B [39]. To the best of our knowledge, this is the first study reporting the association of HTR1B rs13212041 with trait anxiety.

In the present study, we investigated four SNPs in 5-HT1B among 851 individuals of Han Chinese students, including 463 HTA individuals and 388 LTA individuals. According to previously reported observations, there is no functional study available for these SNPs, including rs11568817, rs130058, rs6297, and rs13212041 with trait anxiety, but few studies have investigated their roles in other mental disorders. Evidence of association was found between the functional SNP (rs130058) and alcohol, cocaine, and heroin dependence [40]. 
The rs130058 SNP within 5-HT1B was demonstrated to have a differential association with increasing suicidal ideation depending on the antidepressant type [41]. Some contribution of the functional promoter combination (rs11568817, rs130058)was found with self-reported anger and hostility among young men [20]. The association between three SNPs (rs11568817, rs130058, rs6297) and the susceptibility to schizophrenia and anxiety disorders has not been previously reported [24]. According to previous studies, only a few studies have investigated the association of rs13212041 polymorphism in 5-HT1B with alcohol dependence [17] and schizophrenia [23]. We demonstrated that rs13212041 in 5-HT1B was significantly associated with the personality development of trait anxiety in the Chinese Han population. The frequency of the TC genotype in LTA individuals was significantly higher than in HTA individuals. Both the C-allele, TC genotype, and TC + CC genotype were significantly associated with LTA. FPRP and statistical power were calculated for the positive findings for the samples [42]. At the prior probability level of 0.1 , the significant association for rs13212041 remained noteworthy. Our study provides evidence that rs13212041 may be involved in the protective effect of trait anxiety in China Han college subjects.In future studies, we will explore the potential function of rs13212041 to discover the mechanism of treatment, prevention (through nutritional or environmental changes), and diagnosis.

From the results of bioinformatics analysis, we also found the rs13212041 might affect the proteins bound of 5-HT1B with the FOS gene. FOS genes encode leucine zipper proteins that can dimerise with proteins of the JUN family, thereby forming the transcription factor complex AP-1, which can regulate the expression of 5-HT1B [43]. Based on these, we proposed a hypothesis that rs13212041 could influence the proteins bound of 5-HT1B with the FOS gene, indirectly regulate the downstream gene expression, and affect the expression of 5-HT1B through the gene expression network. The specific mechanism needs to be demonstrated further. Moreover, Jensen et al. characterized the SNP (rs13212041; T1997C) in the distal 3'-UTR of 5-HT1B messenger RNA that disrupts a binding site for miR-96 [44].

MicroRNAs are 20-21 nucleotide ribonucleic acids that regulate gene expression by binding to complementary sites on messenger RNA, triggering mRNA degradation and/or inhibition of translation [45,46]. Jensen et al. showed that the rs13212041 polymorphism modulates the gene expression by binding to miR-96, and the C-allele of rs13212041 may attenuate the regulatory function of miR-96 [44]. In our study, the "TC" genotype and " $\mathrm{C}$ " allele of 5-HT1B rs13212041 were significantly associated with low trait anxiety. The C-allele of rs13212041 appeared to drive the dominant protective effect of trait anxiety. We presumed the "TC" genotype and " $\mathrm{C}$ " allele could disrupt 5-HT1B receptor expression by miR-96. Maybe this pattern suggests that the microRNA-binding site polymorphism has great behavioral effects. Further functional assay is necessary to explore the function and the underlying mechanism of rs13212041 polymorphism.

Given that trait anxiety is a complex disease affected by the interaction of genetic and environmental factors, polygenic or SNP-SNP interaction studies may help to discover the risk factors of trait anxiety. Of note, MDR is a powerful method to detect gene-gene interactions without main gene effects in case-control studies of complex diseases [47]. Further, the MDR was used to analyze the interactions of these four SNPs, the result of the present study suggested that rs13212041 was the best single-locus model to predict trait anxiety and a combination of rs13212041 and rs6297 was the best multi-loci model. The interaction Fruchterman-Reingoldgraph also further confirmed that rs13212041 and rs6297 had a strong correlation, suggesting that HTR1B polymorphisms had an additive effect on the risk of trait anxiety development.

As a fundamental form of genetic variation and inheritance unit, haplotype may affect the phenotypes either directly by affecting promoter activity and protein structure, or indirectly through untyped causal variation near the marker [48]. Therefore, haplotype association is of great significance for revealing the etiology of complex phenotypes. In the study, haplotype analysis implied that haplotype $\mathrm{C}_{\mathrm{rs} 13212041} \mathrm{~T}_{\mathrm{rs} 130058} \mathrm{~T}_{\mathrm{rs} 6297} \mathrm{~A}_{\mathrm{rs} 11568817}$ may 
be a protective haplotype in trait anxiety. Previously, HTR1B haplotypes were associated with HTR1B gene expression [20]. These hinted to us that HTR1B haplotypes could be a potential trait anxiety risk factor.

\section{Limitations}

One of the study limitations is a lack of careful determination of trait anxiety phenotypes, using nuclear magnetic resonance (NMR), electroencephalogram (EEG), and other effective anxiety laboratory indicators. In the future, we would like to enlarge sample size and complete the phenotype information to evaluate the association between 5-HT1B SNPs and trait anxiety phenotypes. In addition, although 5-HT1BSNPs might be associated with trait anxiety, the results were not significant after multiple testing correction $(p<0.05 / 4)$. Thus, the present findings need to be confirmed in future studies with a large sample size. Besides, a replication experiment in a different cohort will strengthen our findings. However, our association analysis firstly displayed that rs13212041 was a susceptible site for anxiety, which might lay a good working foundation for subsequent in-depth experimental molecular research.

\section{Conclusions}

Our study provides a new perspective for understanding the genetic mechanism of trait anxiety personality formation. As far as we know, this is the first study reporting the association of 5-HT1B rs13212041 with trait anxiety. Our results suggest that individuals with rs13212041 C-allele might be associated with the reduced risk of high trait anxiety than carriers with T-allele. Our findings provide novel insights into the serotonergic regulation mechanisms underlying the personality of trait anxiety, which could help in further differentiation of trait anxiety and potential improvement of the therapy for avoiding anxiety disorder.

Author Contributions: Methodology and writing original draft: X.R.; sample collection: S.F.; data collection: Q.Z.; formal analysis: S.Q.; conceptualization and supervision: Y.T.; resources and supervision: W.R. All authors have read and agreed to the published version of the manuscript.

Funding: This research was supported by the Natural Science Foundation of Shaanxi Province (2020JM-306), National Natural Science Foundation of China (81971285), the Fundamental Research Funds for the Central Universities (GK202005001, GK202105001).

Institutional Review Board Statement: Approval was obtained from the Ethics Committee of Shaanxi Normal University. All procedures performed in studies involving human participants were in accordance with the ethical standards of the institutional and/or national research committee and with the 1964 Helsinki Declaration and its later amendments or comparable ethical standards. Informed consent was obtained from all individual participants included in the study.

Informed Consent Statement: Publication consent was obtained from all individual participants included in the study.

Data Availability Statement: The datasets used or analyzed during the current study are available from the corresponding author on reasonable request.

Acknowledgments: We thank all participants who have kindly given their time to participate in our research.

Conflicts of Interest: The authors report no conflicts of interest.

\section{References}

1. Indovina, I.; Robbins, T.W.; Nunez-Elizalde, A.O.; Dunn, B.D.; Bishop, S.J. Fear-conditioning mechanisms associated with trait vulnerability to anxiety in humans. Neuron 2011, 69, 563-571. [CrossRef]

2. Sandi, C.; Richter-Levin, G. From high anxiety trait to depression: A neurocognitive hypothesis. Trends Neurosci. 2009, 32, 312-320. [CrossRef]

3. Bradley, B.P.; Mogg, K.; White, J.; Groom, C.; de Bono, J. Attentional bias for emotional faces in generalized anxiety disorder. Br. J. Clin. Psychol. 1999, 38, 267-278. [CrossRef] 
4. Maner, J.K.; Schmidt, N.B. The role of risk avoidance in anxiety. Behav. Ther. 2006, 37, 181-189. [CrossRef]

5. Mogg, K.; Bradley, B.P. Selective orienting of attention to masked threat faces in social anxiety. Behav. Res. Ther. 2002, 40, 1403-1414. [CrossRef]

6. Dugas, M.J.; Freeston, M.H.; Ladouceur, R.; Rheaume, J.; Provencher, M.; Boisvert, J.M. Worry themes in primary GAD, secondary GAD, and other anxiety disorders. J. Anxiety Disord. 1998, 12, 253-261. [CrossRef]

7. Zmudzka, E.; Salaciak, K.; Sapa, J.; Pytka, K. Serotonin receptors in depression and anxiety: Insights from animal studies. Life Sci. 2018, 210, 106-124. [CrossRef]

8. Sari, Y. Serotonin1B receptors: From protein to physiological function and behavior. Neurosci. Biobehav. Rev. 2004, 28, 565-582. [CrossRef]

9. Nautiyal, K.M.; Tritschler, L.; Ahmari, S.E.; David, D.J.; Gardier, A.M.; Hen, R. A Lack of Serotonin 1B Autoreceptors Results in Decreased Anxiety and Depression-Related Behaviors. Neuropsychopharmacology 2016, 41, 2941-2950. [CrossRef]

10. Groenink, L.; van Bogaert, M.J.; van der Gugten, J.; Oosting, R.S.; Olivier, B. 5-HT1A receptor and 5-HT1B receptor knockout mice in stress and anxiety paradigms. Behav. Pharmacol. 2003, 14, 369-383. [CrossRef]

11. Nautiyal, K.M.; Tanaka, K.F.; Barr, M.M.; Tritschler, L.; Le Dantec, Y.; David, D.J.; Gardier, A.M.; Blanco, C.; Hen, R.; Ahmari, S.E Distinct Circuits Underlie the Effects of 5-HT1B Receptors on Aggression and Impulsivity. Neuron 2015, 86, 813-826. [CrossRef] [PubMed]

12. Lin, D.; Parsons, L.H. Anxiogenic-like effect of serotonin(1B) receptor stimulation in the rat elevated plus-maze. Pharmacol. Biochem. Behav. 2002, 71, 581-587. [CrossRef]

13. Tatarczynska, E.; Klodzinska, A.; Stachowicz, K.; Chojnacka-Wojcik, E. Effects of a selective 5-HT1B receptor agonist and antagonists in animal models of anxiety and depression. Behav. Pharmacol. 2004, 15, 523-534. [CrossRef]

14. Chojnacka-Wojcik, E.; Klodzinska, A.; Tatarczynska, E. The anxiolytic-like effect of 5-HT1B receptor ligands in rats: A possible mechanism of action. J. Pharm. Pharmacol. 2005, 57, 253-257. [CrossRef] [PubMed]

15. Lappalainen, J.; Long, J.C.; Eggert, M.; Ozaki, N.; Robin, R.W.; Brown, G.L.; Naukkarinen, H.; Virkkunen, M.; Linnoila, M.; Goldman, D. Linkage of antisocial alcoholism to the serotonin 5-HT1B receptor gene in 2 populations. Arch. Gen. Psychiatry 1998, 55, 989-994. [CrossRef]

16. Sun, H.-F.; Chang, Y.-T.; Fann, C.S.-J.; Chang, C.-J.; Chen, Y.-H.; Hsu, Y.-P.; Yu, W.-Y.; Cheng, A.T.-A. Association study of novel human serotonin 5-HT(1B) polymorphisms with alcohol dependence in Taiwanese Han. Biol. Psychiatry 2002, 51, 896-901. [CrossRef]

17. Strac, D.S.; Erjavec, G.N.; Perkovic, M.N.; Nenadic-Sviglin, K.; Konjevod, M.; Grubor, M.; Pivac, N. The association between HTR1B gene rs13212041 polymorphism and onset of alcohol abuse. Neuropsychiatr. Dis. Treat. 2019, 15, 339-347. [CrossRef]

18. Popova, N.K. From genes to aggressive behavior: The role of serotonergic system. Bioessays 2006, 28, 495-503. [CrossRef]

19. Olivier, B.; van Oorschot, R. 5-HT1B receptors and aggression: A review. Eur. J. Pharmacol. 2005, 526, 207-217. [CrossRef]

20. Conner, T.S.; Jensen, K.P.; Tennen, H.; Furneaux, H.M.; Kranzler, H.R.; Covault, J. Functional polymorphisms in the serotonin 1B receptor gene (HTR1B) predict self-reported anger and hostility among young men. Am. J. Med. Genet. B Neuropsychiatr. Genet. 2010, 153, 67-78. [CrossRef]

21. Muller, D.; Grevet, E.H.; Panzenhagen, A.C.; Cupertino, R.B.; da Silva, B.S.; Kappel, D.B.; Mota, N.R.; Blaya-Rocha, P.; Teche, S.P.; Vitola, E.S.; et al. Evidence of sexual dimorphism of HTR1B gene on major adult ADHD comorbidities. J. Psychiatr. Res. 2017, 95, 269-275. [CrossRef]

22. Herman, A.I.; Balogh, K.N. Polymorphisms of the serotonin transporter and receptor genes: Susceptibility to substance abuse. Subst. Abus. Rehabil. 2012, 3, 49-57. [CrossRef]

23. Grubor, M.; Zivkovic, M.; Sagud, M.; Nikolac Perkovic, M.; Mihaljevic-Peles, A.; Pivac, N.; Muck-Seler, D.; Svob Strac, D. HTR1A, HTR1B, HTR2A, HTR2C and HTR6 Gene Polymorphisms and Extrapyramidal Side Effects in Haloperidol-Treated Patients with Schizophrenia. Int. J. Mol. Sci. 2020, 21, 2345. [CrossRef]

24. Xia, X.; Ding, M.; Xuan, J.F.; Xing, J.X.; Pang, H.; Wang, B.J.; Yao, J. Polymorphisms in the human serotonin receptor 1B (HTR1B) gene are associated with schizophrenia: A case control study. BMC Psychiatry 2018, 18, 303. [CrossRef]

25. Meier, S.M.; Trontti, K.; Purves, K.L.; Als, T.D.; Grove, J.; Laine, M.; Pedersen, M.G.; Bybjerg-Grauholm, J.; Bækved-Hansen, M.; Sokolowska, E.; et al. Genetic Variants Associated with Anxiety and Stress-Related Disorders: A Genome-Wide Association Study and Mouse-Model Study. JAMA Psychiatry 2019, 76, 924-932. [CrossRef]

26. Purves, K.L.; Coleman, J.R.I.; Meier, S.M.; Rayner, C.; Davis, K.A.S.; Cheesman, R.; Bækvad-Hansen, M.; Børglum, A.D.; Cho, S.W.; Deckert, J.J.; et al. A major role for common genetic variation in anxiety disorders. Mol. Psychiatry 2020, 25, 3292-3303. [CrossRef] [PubMed]

27. Nagel, M.; Jansen, P.R.; Stringer, S.; Watanabe, K.; de Leeuw, C.A.; Bryois, J.; Savage, J.E.; Hammerschlag, A.R.; Skene, N.G.; Muñoz-Manchado, A.B.; et al. Meta-analysis of genome-wide association studies for neuroticism in 449,484 individuals identifies novel genetic loci and pathways. Nat. Genet. 2018, 50, 920-927. [CrossRef]

28. Xu, Z.; Zhang, Z.; Shi, Y.; Pu, M.; Yuan, Y.; Zhang, X.; Li, L.; Reynolds, G.P. Influence and interaction of genetic polymorphisms in the serotonin system and life stress on antidepressant drug response. J. Psychopharmacol. 2012, 26, 349-359. [CrossRef] [PubMed]

29. Gasso, P.; Rodriguez, N.; Blazquez, A.; Monteagudo, A.; Boloc, D.; Plana, M.T.; Lafuente, A.; Lázaro, L.; Arnaiz, J.A.; Mas, S. Epigenetic and genetic variants in the HTR1B gene and clinical improvement in children and adolescents treated with fluoxetine. Prog. Neuropsychopharmacol. Biol. Psychiatry 2017, 75, 28-34. [CrossRef] 
30. Wang, S.; Zhang, K.; Xu, Y.; Sun, N.; Shen, Y.; Xu, Q. An association study of the serotonin transporter and receptor genes with the suicidal ideation of major depression in a Chinese Han population. Psychiatry Res. 2009, 170, 204-207. [CrossRef]

31. Huang, Y.Y.; Oquendo, M.A.; Friedman, J.M.; Greenhill, L.L.; Brodsky, B.; Malone, K.M.; Khait, V.; Mann, J.J. Substance abuse disorder and major depression are associated with the human 5-HT1B receptor gene (HTR1B) G861C polymorphism. Neuropsychopharmacology 2003, 28, 163-169. [CrossRef]

32. Smoller, J.W.; Biederman, J.; Arbeitman, L.; Doyle, A.E.; Fagerness, J.; Perlis, R.H.; Sklar, P.; Faraone, S.V. Association between the 5HT1B receptor gene (HTR1B) and the inattentive subtype of ADHD. Biol. Psychiatry 2006, 59, 460-467. [CrossRef]

33. Davidge, K.M.; Atkinson, L.; Douglas, L.; Lee, V.; Shapiro, S.; Kennedy, J.L.; Beitchman, J.H. Association of the serotonin transporter and 5HT1Dbeta receptor genes with extreme, persistent and pervasive aggressive behaviour in children. Psychiatr. Genet. 2004, 14, 143-146. [CrossRef]

34. Koster, E.H.; Verschuere, B.; Crombez, G.; Van Damme, S. Time-course of attention for threatening pictures in high and low trait anxiety. Behav. Res. Ther. 2005, 43, 1087-1098. [CrossRef]

35. Qi, S.; Luo, Y.; Tang, X.; Li, Y.; Zeng, Q.; Duan, H.; Li, H.; Hu, W. The temporal dynamics of directed reappraisal in high-traitanxious individuals. Emotion 2016, 16, 886-896. [CrossRef] [PubMed]

36. Bland, J.M.; Altman, D.G. Statistics notes. The odds ratio. BMJ 2000, 320, 1468. [CrossRef] [PubMed]

37. Sole, X.; Guino, E.; Valls, J.; Iniesta, R.; Moreno, V. SNPStats: A web tool for the analysis of association studies. Bioinformatics 2006, 22, 1928-1929. [CrossRef]

38. Sharp, T.; Barnes, N.M. Central 5-HT receptors and their function; present and future. Neuropharmacology 2020, $177,108155$. [CrossRef] [PubMed]

39. Jin, H.; Oksenberg, D.; Ashkenazi, A.; Peroutka, S.J.; Duncan, A.M.; Rozmahel, R.; Yang, Y.; Mengod, G.; Palacios, J.M.; O’Dowd, B.F. Characterization of the human 5-hydroxytryptamine1B receptor. J. Biol. Chem. 1992, 267, 5735-5738. [CrossRef]

40. Cao, J.; LaRocque, E.; Li, D. Associations of the 5-hydroxytryptamine (serotonin) receptor 1B gene (HTR1B) with alcohol, cocaine, and heroin abuse. Am. J. Med. Genet. B Neuropsychiatr. Genet. 2013, 162, 169-176. [CrossRef]

41. Perroud, N.; Bondolfi, G.; Uher, R.; Gex-Fabry, M.; Aubry, J.M.; Bertschy, G.; Malafosse, A.; Kosel, M. Clinical and genetic correlates of suicidal ideation during antidepressant treatment in a depressed outpatient sample. Pharmacogenomics 2011, 12, 365-377. [CrossRef]

42. Wacholder, S.; Chanock, S.; Garcia-Closas, M.; El Ghormli, L.; Rothman, N. Assessing the probability that a positive report isfalse: An approach for molecular epidemiology studies. J. Natl. Cancer Inst. 2004, 96, 434-442. [CrossRef] [PubMed]

43. Duan, J.; Sanders, A.R.; Molen, J.E.; Martinolich, L.; Mowry, B.J.; Levinson, D.F.; Crowe, R.R.; Silverman, J.M.; Gejman, P.V. Polymorphisms in the $5^{\prime}$-untranslated region of the human serotonin receptor 1B (HTR1B) gene affect gene expression. Mol. Psychiatry 2003, 8, 901-910. [CrossRef] [PubMed]

44. Jensen, K.P.; Covault, J.; Conner, T.S.; Tennen, H.; Kranzler, H.R.; Furneaux, H.M. A common polymorphism in serotonin receptor 1B mRNA moderates regulation by miR-96 and associates with aggressive human behaviors. Mol. Psychiatry 2009, 14, 381-389. [CrossRef] [PubMed]

45. Selbach, M.; Schwanhausser, B.; Thierfelder, N.; Fang, Z.; Khanin, R.; Rajewsky, N. Widespread changes in protein synthesis induced by microRNAs. Nature 2008, 455, 58-63. [CrossRef] [PubMed]

46. Djuranovic, S.; Nahvi, A.; Green, R. miRNA-mediated gene silencing by translational repression followed by mRNA deadenylation and decay. Science 2012, 336, 237-240. [CrossRef]

47. Ritchie, M.D.; Hahn, L.W.; Roodi, N.; Bailey, L.R.; Dupont, W.D.; Parl, F.F.; Moore, J.H. Multifactor-dimensionality reduction re veals high-order interactions among estrogen-metabolism genes in sporadic breast cancer. Am. J. Hum. Gene 2001, 69, 138-147. [CrossRef]

48. Servin, B.; Stephens, M. Imputation-based analysis of association studies: Candidate regions and quantitative traits. PLoS Genet. 2007, 3, e114. [CrossRef] 